\title{
Uma ferida colonial: Aqui, se narra uma história sem princesas e sem cavalos.
}

\section{A colonial wound: Here, a story is told without princesses and without horses.}

\section{Una herida colonial: Aquí se cuenta una historia sin princesas y sin caballos.}

\section{Aline de Oliveira Rosa ${ }^{1}$}

Resumo: Sabemos que a língua e suas narrativas produzem moldes, assujeitamentos, ideais regulatórios, que normatizam corpxs e produzem histórias, sem que jamais coincidam os que narram (os sujeitos) com os que são narrados (os sujeitados). O que aconteceria se nossxs corpxs falassem, se nossas bocas amordaçadas gritassem o silêncio de todos esses séculos? Não há nada mais urgente do que criarmos um novo vocabulário, fugindo das restrições gramaticais que pesam sobre questões de gênero e de raça, entendendo essas categorias imbricadas, desmantelando as práticas discursivas coloniais e exercendo a afirmação da subjetividade dos corpxs "amerifricanos" na história, nos tornando sujeitos falantes. Levando em conta a intersecção entre racismo e sexismo, ou entre raça e gênero, proponho uma análise da maneira pela qual a estética da branquitude relegou a mulher negra, citando bell hooks, à condição de "objeto sexual disponível” e o que torna relevante, nos dias atuais, é o urgente chamamento - e o faço a partir da mobilização de Lélia Gonzalez, Grada Kilomba, Chimamanda Adichie e a própria bell hooks, entre outras - às vozes historicamente silenciadas para que, numa reapropriação da linguagem, descolonizem o próprio discurso. Mais do que o testemunho de seu tempo, há no texto um projeto, alinhado ao projeto das intelectuais acima mencionadas, de "escrita situada" ou "escrita encarnada", cujo exercício carrega severa crítica às formas discursivas coloniais que se acreditam universais. Assim, me pergunto, para que escrevo Minha resposta, ainda que carregue uma escrita que é ensaiada, na medida em que as palavras e as letras vão se incorporando e dando corpo as texto, num processo oral e escrita: escrevo porque tenho urgência.

Palavras-chave: gênero, raça, descolonialidade, feminismo, linguagem.

Abstract: We know that the language and its narratives produce molds, subjectivities, regulatory ideals, that standardize bodies and produce stories, without ever coinciding those who narrate (the subjects) with those who are narrated (the subjects). What would happen if our bodies spoke, if our gagged mouths screamed the silence of all those centuries? There is nothing more urgent than creating a new vocabulary, avoiding the grammatical restrictions that weigh on gender and race issues, understanding these overlapping categories, dismantling colonial discursive practices and exercising the affirmation of the subjectivity of "Amerifrican" corpxs in history, becoming talking subjects. Taking into account the intersection between racism and sexism, or between race and gender, I propose an analysis of the way in which the whiteness aesthetic relegated black women, citing bell hooks, to the condition of "available sexual object" and what makes it relevant, nowadays, it is the urgent call - and I do it from the mobilization of Lélia Gonzalez, Grada Kilomba, Chimamanda Adichie, bell hooks, among others - to the historically silenced voices so that, in a reappropriation of language, they decolonize the discourse itself. More than the testimony of his time, there is a project in the text, aligned with the project of the intellectuals mentioned above, of "situated writing" or "incarnate writing", whose exercise carries a severe criticism of colonial discursive forms that are believed to be universal. So, I wonder, why do I write My answer, even if it carries a writing that is rehearsed, as the words and letters are incorporated and embody the text, in an oral and written process: I write because I have urgency.

Keywords: gender, race, decoloniality, feminism, language.

Resumen: Sabemos que el lenguaje y sus narrativas producen moldes, sujeciones, ideales reguladores, que estandarizan los cuerpos y producen historias, sin coincidir jamás los que narran (los sujetos) con los que son narrados (los sujetos). ¿Qué pasaría si nuestros cuerpos hablaran, si nuestras bocas amordazadas gritaran el silencio de todos esos siglos? No hay nada más urgente que crear un nuevo vocabulario, evitar las restricciones gramaticales que pesan sobre los temas de género y raza, comprender estas categorías superpuestas, desmantelar las prácticas discursivas coloniales y ejercer la afirmación de la subjetividad de las corporaciones "americanas” en la historia. convirtiéndose en sujetos de conversación. Teniendo en cuenta la intersección entre racismo y sexismo, o entre raza y género, propongo un análisis de la forma en que la estética de la blancura relegó a las mujeres negras, citando campanillas, a la condición de "objeto sexual disponible" y lo que lo hace relevante. hoy en día es el llamado urgente -y lo hago desde la movilización de Lélia González, Grada Kilomba, Chimamanda Adichie y bell hooks, entre otros- a voces históricamente silenciadas para que, en una reapropiación del lenguaje, descolonicen su propio discurso. Más que el testimonio de su tiempo, hay un proyecto en el texto, alineado con el proyecto de los intelectuales antes mencionados, de "escritura situada" o "escritura encarnada", cuyo ejercicio conlleva una severa crítica a las formas discursivas coloniales que se creen universales. Entonces, me pregunto, ¿por qué escribo Mi respuesta, incluso si lleva un escrito ensayado, ya que las palabras y las letras se incorporan y encarnan el texto, en un proceso oral y escrito: escribo porque tengo urgencia.

Palabras clave: género, raza, descolonialidad, feminismo, lengua.

\footnotetext{
${ }^{1}$ Doutoranda em Filosofia e Gênero - UFRJ
}

Copyright (C) 2020 Rosa. Este é um artigo em acesso aberto distribuído nos termos da Licença Creative Commons. Atribuição que permite o uso irrestrito, a distribuição e reprodução em qualquer meio desde que o artigo original seja devidamente citado. 
Me interesa pensar en todo aquello que sale mal en las traducciones, lo que no se puede traducir, las lenguas que hablan mal o las que no se entienden, las lenguas que se meten por otros agujeros, por hoyos inesperados. ${ }^{2}$

\title{
1. Uma história sem sujeitos.
}

"Escrevi exatamente o tipo de história que lia: todos os meus personagens eram brancos de olhos azuis, brincavam na neve, comiam maçãs e falavam muito sobre o tempo e sobre como era bom o sol ter saído. Escrevia sobre isso apesar de eu morar na Nigéria."”, essas foram as palavras de Chimamanda ao descrever suas primeiras escritas aos sete anos de idade. Mesmo nunca tendo saído de seu país, lugar no qual não tinha neve e nem comiam maçãs, e sim mangas, as personagens de Chimamanda carregavam a típica estética branca predominando no que se lia, assistia e ouvia: "Meus personagens também bebiam muita cerveja de gengibre. Não importava que eu não fizesse ideia do que fosse cerveja de gengibre." ${ }^{4} \mathrm{O}$ que resultou em um desejo, conta a autora, que carregou por muitos anos, experimentar a famosa bebida de gengibre. Chimamanda ressalta a importância de lermos e escrevermos nossas histórias, sendo a história marca ou não de um grupo, de um povo e de uma cultura.

Essa narrativa demonstra um imaginário cruel ao qual muitas meninas negras - assim como os corpos latinoamericanos não-brancos se prendem. Nossas crianças são o tempo todo submetidas a adorar e cobiçar as imagens de beleza branca projetadas nas revistas, as princesas salvas pelos príncipes nos livros infantis, os cabelos lisos e loiros das donzelas nas novelas, os vestidos de fita amarela na cintura, as unhas vermelhas, os saltos e as meias finas tão delicadas que só uma madama usaria sem puxar fios e sujá-las. Um imaginário excludente de beleza que nossas meninas e mulheres latinas nunca poderão realizar, não porque sejam inferiores, mas porque sua beleza, suas práticas e suas narrativas são outras. Esse discurso reproduzido incessantemente sobre o que é ser uma mulher bonita apaga e desumaniza corpos não-brancos, inferiorizando suas cinturas e quadris largos, seus olhos negros, seus cabelos crespos, cacheados, ondulados e suas cores de pele. E, para que uma menina não branca seja considerada bonita, sua beleza é o tempo todo negada e sujeitada a violências estéticas. Sobre esse estereótipo de beleza branca introjetada, Lélia Gonzalez nos lembra:

\begin{abstract}
Tem uma música antiga chamada "Nêga do cabelo duro" que mostra direitinho porque eles querem que o cabelo da gente fique bom, liso e mole, né? É por isso que dizem que a gente tem beiços em vez de lábios, fornalha em vez de nariz e cabelo ruim (porque é duro). $\mathrm{E}$ quando querem elogiar a gente dizem que a gente tem feições finas (e fino se opõe a grosso, né?). E tem gente que acredita tanto nisso que acaba usando creme prá clarear, esticando os cabelos, virando leidi e ficando com vergonha de ser preta. Pura besteira. ${ }^{5}$
\end{abstract}

\footnotetext{
${ }^{2}$ Emma Álvarez e Nahuala Brunel, Afectos y disidencias sexuales jota-cola-mariconas en Abya Yala (Buenos Aires: Madrágoras de Fuego, 2018), 7.

${ }^{3}$ Chimamanda Ngozi Adichie, O perigo de uma história única (São Paulo: Companhia das Letras, 2009 ), 7.

${ }^{4}$ Ibid., 7.

${ }^{5}$ Lélia Gonzalez, “Racismo e sexismo na cultura brasileira”. Revista Ciências Sociais Hoje (1984): 234.
} 
Me lembro da menina de nove anos, personagem de Morrison, chamada Pecola, em $O$ olho mais azul Toni Morrison a descreve sempre preocupada com a sua "feiura" de ter uma pele escura e olhos negros e não uma pele clara e os olhos azuis das atrizes de cinema, como gostaria de possuir. Em seu posfácio a autora pergunta: "Por que, embora insultada por outros, essa beleza não podia ser considerada válida dentro da comunidade? Por que precisava ser explicada e divulgada ao grande público para existir?" Essas perguntas que Morrison faz em 1962 nos EUA, na sua cidade natal de Lorain em Ohio, ecoam ainda hoje e retratam uma herança histórica colonial. Nesse discurso, a beleza da mulher negra é recorrentemente inferiorizada e, mesmo quando elogiada, é sexualizada e fetichizada.

Ainda falando sobre as personagens do conto de Morrison, que retratam um racismo cotidiano violento e que prescrevem uma estética branca totalmente nociva, me lembro da personagem Maureen, a colega de escola branca que todos amavam. Um dia voltando da escola, Maureen insulta Claudia, sua irmã Frieda e a amiga Pecola dizendo: "Eu sou bonita! E vocês são feias! Pretas e feias, pretas retintas. Eu sou bonita!"7 . Frases repletas de um imaginário do que é belo e bom, contatos décadas após décadas de que ela, a menina branca de olhos azuis, é a representação da beleza e que Pecola e as amigas são inferiores por terem suas pelas negras e olhos escuros. Claudia diz: "Se ela era bonita - e se havia uma coisa em que acreditar era que ela era -, então nós não éramos. E o que é que isso significava? Éramos inferiores. Mais simpáticas, mais inteligentes, mas, ainda assim, inferiores." 8 A coisa a temer na história de Morrison é a beleza, ou a falta de uma, "a Coisa que tornava bonita a ela e não a nós"9 é o racismo imperativo de cor, que faz com que tantas meninas e mulheres não-brancas percam o amor a si mesmas.

No romance de Morrison percebemos como as narrativas e as histórias estão presentes e constroem o imaginário das crianças e mulheres negras, de histórias em histórias repetidas monta-se uma sociedade patriarcal-racista-sexista. Em uma ocasião a mãe da personagem Pecola, Sra Paulina, vai pela primeira vez ao cinema e sobre essa experiência a autora Morrison escreve: "Lá, no escuro, sua memória se reavivou e ela sucumbiu aos sonhos antigos. Além da ideia de amor romântico, foi apresentada a outra — à da beleza física." ${ }^{10} \mathrm{O}$ cinema foi para Paulina sua primeira inserção social e cultural de uma vida marcada por fragmentação e isolamento de raça e classe. Paulina teve contato com o ideal de beleza branca e não pode se reconhecer nas telas de cinema, o que a levou ao sonho de um dia ser como elas. Pecola, a filha, carregava da mãe esse mesmo ideal de beleza, havia a caneca

\footnotetext{
${ }^{6}$ Toni Morrison, O olho mais azul (São Paulo: Companhia das Letras, 2009), 403.

${ }^{7}$ Ibid., 139.

${ }^{8}$ Ibid., 141.

${ }^{9}$ Ibid., 142.

${ }^{10}$ Ibid., 231.
} 
de leite que ela bebia bem de vagar contemplando a figura de Shirley Temple, apenas para ver a rosto branco da atriz.

A personagem Pecola tinha convicção de que ela era feia e fora amaldiçoada por deus por ter aquela pele e aqueles olhos negros. Em uma ocasião, a menina vai até o charlatão religioso Soaphead, que dizia ter recebido um dom de deus para realizar desejos em troca de algumas moedas, e diz: "Meus olhos. Eu quero que eles sejam azuis". Soaphead declara: “Ali estava uma menina feia pedindo beleza. (...) Uma menina negra que desejava alçar-se para fora do fosso de sua negritude e ver o mundo com olhos azuis"11. A frase de Soaphead descreve as cicatrizes da psique da menina negra diante de uma sociedade racista. Ainda no posfácio do livro, Morrison afirma: “Concentrei-me, então, em como algo tão grotesco quanto a demonização de uma raça inteira podia criar raízes dentro do membro mais delicado da sociedade: uma criança; do membro mais vulnerável: uma mulher."12

Assim como no romance de Morrison, também vemos no cotidiano das brasileiras a inferiorização da beleza "amerifricana"13, o cabelo negro recorrentemente associado ao sujo, ao feio, ao bagunçado, “cabelo ruim"... no entanto, se o dread aparece no cabelo loiro da atriz branca da novela, é lindo e jamais seria sujo. Aqui ainda presenciamos mais um problema, o da apropriação cultural, visto que o dread é um marcador cultural da ancestralidade negra. E é por isso que me proponho a discutir sobre as narrativas históricas e a situação da mulher brasileira na atualidade. Discurso este que não pode estar desconectado das questões raciais e de gênero, ou seja, quando falamos da mulheridade brasileira não podemos esquecer que estamos falando de questões de gênero que envolve questões racistas, ou como chama Grada Kilomba, um "racismo genderizado". ${ }^{14}$

Chimamanda conta que, quando foi fazer faculdade nos EUA, sua colega de quarto ficou chocada quando percebeu que ela falava inglês, ela não sabia que na Nigéria a língua oficial é o inglês. A mesma perguntou a Chimamanda se poderia ouvir o que ela chamava de sua "musica tribal"15, a autora fala que a amiga ficou decepcionada quando mostrou sua fita da Mariah Carey, "ela já sentia pena de mim antes de me conhecer. Sua postura preestabelecida em relação a mim, como africana, era uma espécie de pena condescendente e bem-intencionada." ${ }^{16}$ Sua colega de quarto tinha uma história única da África, uma história de catástrofe, violência, fome e dor. Isso não significa dizer que não haja todos esses problemas na África, assim como em qualquer outro país que tenha sido explorado e saqueado pelos EUA e pelos países europeus, mas uma história única não nos permite ter acesso a tantas outras coisas que constituem a África. Chimamanda afirma que se ela não tivesse nascido na Nigéria e se tudo o que soubesse sobre a África viesse das imagens populares,

\footnotetext{
${ }^{11}$ Ibid., 341.

12 Ibid., 404.

${ }^{13}$ Lélia Gonzalez, "Racismo e sexismo na cultura brasileira". Revista Ciências Sociais Hoje (1984): 9.

${ }^{14}$ Grada Kilomba, Memórias da plantação: episódios de racismo cotidiano, (Rio de Janeiro: Cobogó, 2019 ), 93.

${ }^{15}$ Chimamanda Ngozi Adichie, O perigo de uma história única (São Paulo: Companhia das Letras, 2009$), 9$.

${ }^{16}$ Ibid., 9.
} 
"também ia achar que se tratava de um lugar com pessoas incompreensíveis travando guerras sem sentido, morrendo de pobreza e de AIDS, incapazes de falar por si mesmas e esperando para serem salvas por um estrangeiro branco e bondoso." 17

Podemos ver essas histórias únicas acerca das mulheres latinas quando associadas a serviços de empregadas domésticas e negras a serviços ligados ao sexo por serem chamadas de "corpos quentes" na literatura. E ainda quando o acesso médico é negligente com mulheres negras associando esses corpos a "boas parideiras natas". Mais uma vez retomo a personagem Paulina de Toni Morrison em Olhos mais azuis, ela diz:

\begin{abstract}
Quando chegou a minha vez, ele disse que com essas mulher vocês não têm problema algum. Elas dão à luz logo e sem dor. Exatamente como as égua. (...) Eu vi eles conversando com as mulher branca: 'Como está se sentindo? Vai ter gêmeos?'. Conversa à toa, claro, mas conversa boa. (...) Gemi muito. As dor não tava assim tão forte, mas eu tinha que fazer aquela gente saber que ter um bebê era mais do que ter vontade de ir no banheiro. Eu sentia tanta dor quanto as branca. E também aquele médico não sabia o que tava falando. Ele nunca deve ter visto uma égua parir. Quem disse que ela não sente dor? Só porque não grita? Eles pensa que a dor não tá lá? Se eles olhasse no olho dela e visse os globo arregalado, visse o olhar aflito, eles ia saber. ${ }^{18}$
\end{abstract}

Essas são formas de objetificar pessoas, ou seja, elas são vistas como objetos de suas histórias e não como autoras. "É assim que se cria uma história única: mostre um povo, comovam coisa, uma coisa só, sem parar, e é isso que esse povo se torna." "19 Essa relação de contar histórias únicas constrói os pilares de uma sociedade racista e sexista.

No Brasil, a mulher negra é vítima de agressões a sua psique e ao seu corpo. Podemos ter como exemplo o recente episódio racista que ocorreu no Colégio Franco-Brasileiro na Zona Sul do Rio de Janeiro. Ndeye Fatou Ndiaye, uma adolescente negra que estuda nessa escola, foi vítima de racismo em mensagens trocadas num grupo de alunos no WhatsApp. Ndeye foi xingada e humilhada apenas por ser uma menina negra. Os textos das mensagens continham frases extremamente racistas: "Para comprar um negro, só com outro negro mesmo"20, diz uma das mensagens. "Quanto mais preto, mais preju" 21, "Dou dois índios por um africano" 22 , "Um negro vale uma bala" ${ }^{23}$, "Fede a chorume" 24 , "Ela não usa sutiã? Não, escravo não pode. Ela não é gente" ${ }^{25}$. Nas frases vemos que a menina, descrita pelos professores como inteligente e dedicada, é atacada simplesmente por ser negra e afrodescendente. Racismo este que não faz parte do passado, mas está presente no cotidiano dos

\footnotetext{
17 Ibid., 10.

${ }^{18}$ Toni Morrison, O olho mais azul (São Paulo: Companhia das Letras, 2009), 419-420.

${ }^{19}$ Chimamanda Ngozi Adichie, O perigo de uma história única (São Paulo: Companhia das Letras, 2009 ), 12.

${ }^{20}$ Ana Paula Santos. "Estudante é vítima de racismo em troca de mensagens de alunos de escola particular da Zona Sul do Rio.” O Globo. https://g1.globo.com/rj/rio-de-janeiro/noticia/2020/05/20/estudante-e-vitima-de-racismo-em-troca-demensagens-de-alunos-de-escola-particular-da-zona-sul-do-rio.ghtml.

${ }^{21}$ Ibid.

22 Ibid.

${ }^{23}$ Ibid.

${ }^{24}$ Ibid.

25 Ibid.
} 
brasileiros. Em uma entrevista o pai de Ndiaye afirma: "Tudo é a questão racial. Porque a pessoa que atira o gatilho, que faz tudo isso, na realidade, faz isso por causa do sistema. Eu desconheço algum negro brasileiro que não tenha sofrido racismo". ${ }^{26}$

Assim também podemos lembrar de como a jornalista e apresentadora do Jornal Hoje da emissora Globo, Maria Júlia Coutinho Portes, conhecida como Maju Coutinho, foi vítima de forma violenta nas redes sociais: "Vai lavar roupa seu lugar não é aí"27, disse Wadson José, que se identifica no Facebook como "Raça Porco"28 "Nega nojenta"29, "Continua sendo preta nojenta"30 afirmou Gilson Duram, um cidadão que posta foto dele com a família branca feliz comendo bolo de aniversário. Maju ao se tornar âncora do jornal do meio dia foi diversas vezes agredida não somente por ser negra, mas também por ser mulher, os xingamentos pejorativos associados a ela eram de uma mulher depravada, que fazia uso de insinuações sexuais para ocupar um lugar de destaque, chama de "mulata boa de cama”, etc. Alguns, ainda que para elogiá-la, diziam "ela é linda, só podia baixar um pouco seu cabelo", frase que ouvi de minha avó assistindo ao jornal. Me pergunto, qual mulher negra não passou por racismo genderizado no Brasil?

Para bell hooks a mulher negra passa por uma dupla opressão, pois estando na base da pirâmide de uma sociedade patriarcal, ela é alvo de violência racista praticada por mulheres e homens brancos e também é alvo de violência de gênero praticada por homens brancos e negros. bell hooks afirma: "Mesmo que uma mulher negra se tornasse advogada, médica ou professora, era provável que ela fosse rotulada, por brancos, de meretriz, prostitutas. Todas as mulheres negras, independentemente de sua circunstância, eram agrupadas na categoria de objetos sexuais disponíveis." ${ }^{31}$ O tempo verbal no pretérito em "era" de hooks trocamos pelo presente do indicativo “é”, pois esse comportamento direcionado às mulheres é o fato inescapável dos dias atuais e vai além da classe social, opera por imbricações de raça, gênero, etnia, etc.

A partir de bell hooks podemos ver como as mulheres negras são depreciadas ainda hoje, sendo este um legado da escravidão, "a designação de todas as mulheres negras como depravadas, imorais e desinibidas sexualmente surgiu no sistema de escravidão" ${ }^{32}$ e, no entanto, no período pósescravidão se criou o estereótipo da mulher negra, isto é, os mitos da mulher negra como "permissiva em relação ao sexo, como disponíveis e ansiosas por receberem violações sexuais de quaisquer homens, negros ou brancos. ${ }^{33} \mathrm{E}$ foi assim que homens e mulheres brancas justificaram a exploração

\footnotetext{
26 Ibid.

27 Joaquim de Carvalho. "Maju da Globo é vítima de ataques racistas por apoiadores de Bolsonaro". DCM. https://www.diariodocentrodomundo.com.br/maju-da-globo-e-vitima-de-ataques-racistas-por-apoiadores-de-bolsonaro/.

28 Ibid.

${ }^{29}$ Ibid.

${ }^{30}$ Ibid.

${ }^{31}$ bell hooks, E eu não sou uma mulher? Mulheres negras e feminismo (Rio de Janeiro: Rosa dos Tempos, 2019 ), 102.

${ }^{32}$ Ibid., 93.

${ }^{33}$ Ibid., 93.
} 
sexual de mulheres negras, argumentando que eram elas que buscavam tal exploração, que eram elas que iniciavam envolvimento sexual com homens brancos, eles eram apenas vítimas da sensualidade e sedução de mulheres negras, como se estivessem sendo enfeitiçados pelo canto da sereia preta. Desse pensamento, emergiu o estereótipo de mulheres negras como "selvagens sexuais e, em termos sexistas, uma selvagem sexual, não humana, animal não é estuprada." ${ }^{34}$ Um discurso bem similar está presente hoje quando ouvimos falar de meninas que são estupradas, "elas que pediram", "porque estavam de saia curta naquele lugar", "aposto que foi ela que seduziu o tio".

A criação desse imaginário da mulher negra como hiper sexualizada e disponível para o sexo, na escravidão, era sobretudo uma questão lucrativa e de dominação dos homens sobre suas posses de escravas. Com a abolição da escravatura esse imaginário e mito persistem, mesmo depois de décadas, por quê? Por que mesmo casada, solteira, crianças ou adultas, a mulher negra continua como alvo suscetível para estupradores? E por que sua imagem é sempre inferiorizada a partir de sua sexualidade? Quando homens e mulheres brancas afirmam que a mulher negra é promiscua, sexualmente selvagem, eles estão tornando o corpo negro imoral, portanto, inferior e impossível de serem iguais aos corpos brancos. "Todas as mulheres negras eram, por definição, vagabundas, de acordo com essa mitologia racista. Sendo assim, violentadas e exploradas sexualmente." 35 Para hooks não há dúvidas de que "a desvalorização da mulher negra depois do término da escravidão foi um esforço consciente e deliberado dos brancos para sabotar a construção da confiança e do autorrespeito da mulher negra." ${ }^{36}$ A sistemática desvalorização da mulheridade negra não foi uma simples consequência do ódio racial, mas um método calculado de controle social que fazia parte de um modelo de sociedade patriarcal eurocêntrica. Sobre este mesmo tema Federici em Calibã e a bruxa afirma:

[...] a sexualização exagerada das mulheres e dos homens negros — as bruxas e os demônios - também deve ter como origem a posição que ocupavam na divisão internacional do trabalho surgida com a colonização da América, com o tráfico de escravos e com a caça às bruxas. A definição da negritude e da feminilidade como marcas da bestialidade e da irracionalidade correspondia à exclusão das mulheres na Europa — assim como das mulheres e dos homens nas colônias — do contrato social implícito no salário, com a consequente naturalização de sua exploração." 37

Hoje vemos ainda esse legado pesar sobre os corpos de mulheres negras. As fantasias, os mitos, não desaparecem simplesmente, uma história contada não é apagada com o tempo, por isso é preciso descolonizar o próprio discurso, reinventar novas maneiras de escrever e falar, novas línguas, novas histórias, dando ressignificados as já existentes. Não há como apagar uma história de colonização, mas podemos desconstruí-la, descolonizando os corpos. Criando nossas próprias

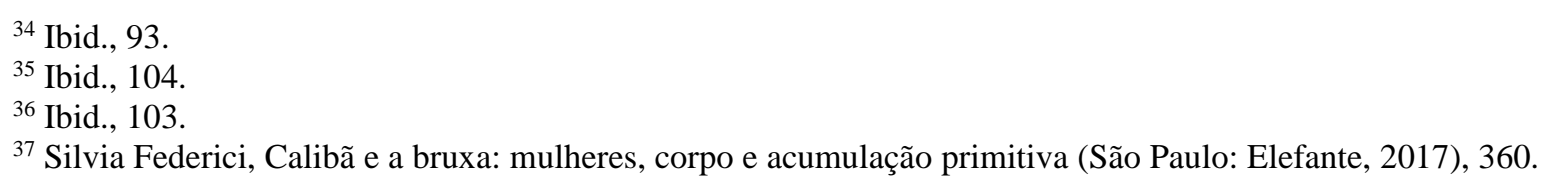


histórias, a partir de práticas e linguagens novas. Este não é um chamado para criar novos mitos, mas para narrar nossas experiências, com as quais outras pessoas possam se identificar. Trata-se de dizer não à veiculação de uma única história. Escrever contra significa falar contra o silêncio e a marginalidade criados pelo racismo e sexismo, descolonizando nosso imaginário. Essa é uma luta constante de ocupar espaços de poder para que se possa modificar o substrato histórico-social. Esse processo requer "o entendimento da própria marginalidade, o que cria a possibilidade de devir como um novo sujeito" 38 . Só fazer parte da margem não quer dizer devir um novo e transformar suas relações, é preciso conhecer o seu lugar e como o seu corpo está ligado a ele.

Por isso, é preciso escrever, dizer, gritar, uma manifestação contra histórica, um desmantelamento das narrativas coloniais e nos tornarmos autores das nossas próprias histórias, falarmos de um lugar nosso. No livro Histórias das mulheres; Histórias feministas, resultado da edição da exposição do MASP, no ano passado, Mariana Leme, curadora assistente do museu, diz: "a maneira como vemos as coisas é afetada por aquilo que conhecemos ou acreditamos"39. Para que se possa reconhecer as diversas histórias, histórias de mulheres e pessoas não-brancas, é necessário atentar para a seguinte pergunta: "de que maneira as categorias de classificação simbólica condicionam as leituras das obras e as impressões do mundo, que por sua vez informam a narrativa canônica branca, masculina e eurocêntrica?" 40 Por isso, é tão importante contar as nossas histórias, nossas experiencias, para que outrxs possam se identificar com. Quando Chimamanda começa sua palestra dizendo "sou uma contadora de histórias" 41 , ela está tomando posse de um lugar que não lhe era reconhecido, o que Grada Kilomba vai chamar de "se tornar sujeito e escritor da sua própria história." 42

\subsection{O silêncio de muitxs.}

Quando falamos de uma história única, é impossível não falar de poder. Como dizia Foucault, o saber opera por discursos, todo discurso se constrói segundo um jogo constante de permissões e restrições, não havendo discurso sem poder, nem saber sem que esteja ligado a relações de poder. E um e outro, saber e poder, estão ligados ao desejo: no fundo das relações humanas há o desejo. O que faz com que o poder seja aceito e que simplesmente ele não apareça e seja percebido como uma força violenta e repressora é que, em sua vinculação com o desejo, o poder seduz, captura, se insere nos corpos, produz discursos, histórias, ciências... Portanto, é preciso perguntar: quem é aquele que

\footnotetext{
${ }^{38}$ Grada Kilomba, Memórias da plantação: episódios de racismo cotidiano, (Rio de Janeiro: Cobogó, 2019 ), 69.

${ }^{39}$ MASP, Histórias das mulheres, Histórias feministas (São Paulo: MASP, 2019), 19.

${ }^{40}$ Ibid., 19.

${ }^{41}$ Chimamanda Ngozi Adichie, O perigo de uma história única (São Paulo: Companhia das Letras, 2009$), 7$.

${ }^{42}$ Grada Kilomba, Memórias da plantação: episódios de racismo cotidiano, (Rio de Janeiro: Cobogó, 2019 ), 28.
} 
pronuncia o discurso? "Aquele que tem a possibilidade de formar verdades" ${ }^{43}$, este detém o poder, "o poder de poder dizer a verdade e de expressá-la como quiser." ${ }^{44}$. Ou seja, a verdade está ligada ao discurso da época, a histórias criadas, sendo a verdade discursiva. E o poder é a habilidade não apenas de contar história sobre outras pessoas, mas também de fazer com que ela seja sua história definitiva.

Assim, só quando se reconfiguram as estruturas de poder é que as identidades marginalizadas podem aparecer, e assim se reconfigurar a noção de conhecimento. Nesse processo, a língua nos informa quem é normal e quem pode representar a verdadeira noção de humano, de reconhecido. Em uma sociedade onde a língua é estrutura do patriarcado branco heteronormativo, outras formas de subjetividades são inviabilizadas. O próprio termo "sujeito" no português é reduzido ao gênero masculino - o sujeito -, sem permitir variações no gênero feminino - a sujeita - ou nos vários gêneros LGBTTQIA+ - xs sujeitxs -, estes são identificados como erros ortográficos. "É importante compreender o que significa uma identidade não existir na sua própria língua, escrita ou falada, ou ser identificada como um erro. Isto revela a problemática das relações de poder e violência na língua portuguesa, e a urgência de se encontrarem novas terminologias." 45

Por isso não há nada mais urgente do que criarmos uma nova língua, um novo vocabulário que reconheça todxs em condição humana, desmontando a língua colonial. Esse é um ato de resistência a um sistema patriarcal, que produz práticas discursivas, exercendo uma linguagem plural e a subjetividade. Por isso, Paul Preciado se refere a nós como a "corpos falantes" 46 na desconstrução de uma linguagem heteronormativa, tomando suas próprias palavras, reclamando sua própria identidade. Para Preciado, xs corpxs são como textos, "um sistema de escritura"47 que não é apenas um discurso linguístico, “o corpo é um texto socialmente construído, um arquivo orgânico da história da humanidade como história da produção-reprodução sexual, na qual certos códigos se naturalizam" 48 , sendo o biológico por si só não natural. Assim, a heterossexualidade, longe de surgir espontaneamente nos corpos recém nascidos, é inscrita nos corpos através de "operações constantes de repetição e de recitação dos códigos (masculino e feminino) socialmente investidos como naturais" $"$. Da mesma forma que a heterossexualidade é "contranatura" 50 , assim também é o racismo, que transforma sujeitos em objetos, que se reproduz através dos rituais sociais, através das histórias e dos imaginários coletivos. Por isso é preciso vomitar uma estrutura letal ingerida pelos corpos forçosamente, destruindo a língua normativa. Resgatando uma antropofagia cultural, que surge com

\footnotetext{
${ }^{43}$ Michel Foucault, Ditos e escritos, volume V: ética, sexualidade, política (Rio de Janeiro: Forense Universitária, 2012), 277.

${ }^{44}$ Ibid., 277.

${ }^{45}$ Grada Kilomba, Memórias da plantação: episódios de racismo cotidiano (Rio de Janeiro: Cobogó, 2019 ), 15.

${ }^{46}$ Paul B. Preciado, Manifesto contrassexual (São Paulo: n-1 edições, 2017), 21.

${ }^{47}$ Ibid., 27.

48 Ibid., 26.

${ }^{49}$ Ibid., 26.

${ }^{50}$ Ibid., 26.
} 
os modernistas (lembremos de "O Manifesto Antropofágico") e é inspirada, como se sabe, nos rituais antropofágicos indígenas. Este “devorar a língua”, não deve ser entendido como um “devorar” da língua normativa, já que todas as variedades linguísticas do português do Brasil manifestam, em maior ou em menor grau, traços racistas e/ou sexistas. Mas é chegada a hora de uma antropofagia linguística que seja capaz de dar voz aos grupos silenciados, um comer das línguas esquecidas, Abya Yala.

Assim, falar e escrever a nossa linguagem é ato de nos tornarmos sujeitos, desconstruindo um sistema patriarcal-racista e heteronormativo. Lélia Gonzalez faz esse trabalho quando não abre mão de escrever palavras do seu vocabulário cotidiano, transgredindo a norma eurocêntrica e colonial do saber, criando novas palavras e chamando nossa língua de "pretoguês":

É engraçado como eles gozam a gente quando a gente diz que é Framengo. Chamam a gente de ignorante dizendo que a gente fala errado. $E$ de repente ignoram que a presença desse $r$ no lugar do l, nada mais é que a marca linguística de um idioma africano, no qual o 1 inexiste. Afinal, quem que é o ignorante? Ao mesmo tempo, acham o maior barato a fala dita brasileira, que corta os erres dos infinitivos verbais, que condensa você em cê, o está em tá e por aí afora. Não sacam que tão falando pretuguêss. ${ }^{51}$

Por isso é necessário que ocupemos todos os espaços possíveis, transformando os discursos e reconhecendo as condições internas e mais profundas das desigualdades. É hora de pôr o dedo na ferida colonial e acabar com, como diz Lélia, o "orgulho besta de dizer que a gente é uma democracia racial" 52 , sendo este um racismo por omissão e abandono de corpos periféricos. Falar a própria língua é ir contra uma história de silêncios, de vozes torturadas, línguas rompidas, idiomas impostos, discursos infantilizados. É dar voz a uma fome coletiva.

Nós mulheres e não brancas fomos "faladas", definidas e classificadas por um sistema ideológico de dominação que nos infantiliza. Ao nos impor um lugar inferior no interior da sua hierarquia (apoiadas nas nossas condições biológicas de sexo e raça), suprime nossa humanidade justamente porque nos nega o direito de sermos sujeitos não só do nosso próprio discurso, como da nossa própria história. É desnecessário dizer que, com todas essas características, estamos nos referindo ao sistema patriarcal-racista. ${ }^{53}$

Grada Kilomba faz reviver o poema de Jacob Sam-La Rose: "Por que escrevo? Porque eu tenho de, porque minha voz, em todos seus dialetos, tem sido calada por muito tempo" ${ }^{54}$. Aqui, reforça-se a ideia de que "a história pode ser interrompida, apropriada e transformada através da prática artística e literária" 55 . A partir de uma nova linguagem e da criação de uma nova metodologia de escrita, que não é universal, mas singular, quase que como contos, Kilomba diz: "escrever esse

\footnotetext{
${ }^{51}$ Lélia Gonzalez, "Racismo e sexismo na cultura brasileira”. Revista Ciências Sociais Hoje (1984): 238.

52 Ibid., 239.

${ }^{53}$ Lélia Gonzalez, "Por um feminismo afro-latino-americano". Pensamento feminista hoje: perspectivas decoloniais (2020): 38 .

${ }^{54}$ Grada Kilomba, Memórias da plantação: episódios de racismo cotidiano (Rio de Janeiro: Cobogó, 2019 ), 27.

55 Ibid., 27.
} 
livro foi, de fato, uma forma de transformar, pois aqui eu não sou a "Outra", mas sim eu própria. Não sou o objeto, mas o sujeito." 56

O sujeito se constitui pelas vias da linguagem como sujeito falante, escrever é um ato de tornar-se. Enquanto escrevo, eu sou autora da minha própria história e narradora da minha própria realidade, invento a mim mesma, na exata ocasião em que me torno sujeita dos fatos que narro. A partir daí, a narrativa se expande, se somam a ela vozes antes silenciadas, num processo de identificação. Quando isso ocorre há um estranhamento cultural e linguístico: sujeitas, rompendo com estrutura da língua.

Assim, toda história guarda consigo o silêncio daqueles que não são mencionados, aqueles que não puderam falar, isso porque cada história carrega um ideal e uma estética os quais se quer preservar como universais e únicos. Assim se silenciou por anos histórias de pessoas não-brancas e de mulheres em relação ao mundo masculino, eliminando memórias e heranças. Se, como afirma Preciado, corpos são "um sistema de escritura", nós, mulheres negras, fomos transformadas em uma língua morta, uma voz proibida.

Grada Kilomba nos traz em seu livro Memórias de plantação a imagem da escrava Anastácia amordaçada com uma máscara, muito utilizada em escravas. A boca que simboliza a fala e a enunciação toma lugar de silenciamento e tortura, senso de mudez. A máscara representa o colonialismo, as políticas sádicas de conquista e dominação, e seus regimes brutais de silenciamento. Impedir o indivíduo de falar sobre sua história é fazer com que sua história seja esquecida e soterrada pela colonização. A boca se torna um órgão de controle e opressão, seu amordaçamento tira dos corpos o direito de serem sujeitos e autores de sua própria história. No entanto, o que aconteceria se as escravas pudessem falar? O que delatariam? O que não podia ser dito a ponto de ser tão brutalmente silenciado? Por que a boca da escravizada tem de ser fechada? O que ela não pode dizer?

O colonialismo patriarcal durante muito tempo mascarou suas violências nos silêncios mascarados. O homem branco não podia ser confrontado, seus desejos, suas psiques, suas projeções do "eu" no "outro", eram guardadas em segredo. Assim como, não muito tempo atrás, segredos racistas, misóginos, homofóbicos, lesbofóbicos eram silenciados atrás de um discurso da "boa família brasileira". Quando esse processo de silenciamento começou a ser confrontado, desmascarado, e pessoas se sentiram incentivadas, por um presidente fascista, a externar seus desejos, transferências e sentimentos, as violências e preconceitos apareceram nas falas dos "pais de famílias" e "homens bons", a família brasileira colonialista. A repressão é, nesse sentido, a defesa que o ego encontra para controlar e censurar.

[...] aquelas/es que são ouvidas/os são também aquelas/es que "pertencem”, aquelas/es que não são ouvidas/os se tornam aquelas/es que "não pertencem". A máscara recria esse projeto

\footnotetext{
${ }^{56}$ Ibid., 27.
} 
de silenciamento e controla a possibilidade de que colonizadas/os possam um dia ser ouvidas/os e, consequentemente, possam pertencer. ${ }^{57}$

Quando não discutimos questões de gênero e racismo juntos, estamos negligenciando e silenciando experiências individuais. A "construção racista baseia-se em papéis de gênero e vice e versa. E gênero tem um impacto na construção de raça e na experiência do racismo"58. Por exemplo, a construção do mito da mulher negra disponível e hiper sexualizada, da mulher branca como pura, bem como da sororidade universal feminista e do homem branco como herói. É preciso pensar o feminismo como uma questão interseccional, que se preocupa com as experiências subjetivas de cada mulher, que presencia de formas distintas questões de racismo, misoginia, homofobia, inserida no seu território, continente, etnia, etc.

A respeito, Grada Kilomba afirma: "Uma grande parte das políticas negras construiu seus sujeitos em torno de concepção de masculinidade heterossexual negra. A construção do sujeito negro como masculino é problemática porque invisibiliza experiências de mulheres e pessoas LGBTTQIA+ negras" ${ }^{\text {"59 }}$. Essa concepção simplesmente transforma o homem branco heterossexual em homem negro heterossexual, como também o homem branco machista e sexista em homem negro machista e sexista. Assim como é preciso trazer a questão do racismo para dentro dos problemas de gênero, também é preciso pensar o movimento feminista negro a partir de questões de gênero. Mulheres negras são desprestigiadas diante do privilégio de mulheres e homens brancos, mas também mulheres negras sofrem questões sexistas e misóginas de homens brancos e negros. Homens brancos e homens negros compartilham de um sexismo, ambos acreditam na inferioridade natural da mulher e apoiam o domínio do homem no mercado de trabalho, nos lares, na política etc. bell hooks afirma:

\begin{abstract}
Enquanto o movimento Black Power dos anos 1960 foi uma reação contra o racismo, foi também um movimento que permitiu aos homens negros anunciar publicamente seu apoio ao patriarcado. Homens negros militantes atacavam publicamente os patriarcas brancos por seu racismo, mas também estabeleciam uma conexão de solidariedade com eles, baseados na aceitação do patriarcado e no comprometimento com esse sistema que compartilhavam. ${ }^{60}$
\end{abstract}

Assim se manteve a ordem patriarcal colonial, introjetada por homens negros. Entre homens brancos e homens negros é exercido um patriarcado e sexismo como forma de dominação das mulheres. Este é um erro do feminismo negro em não considerar o sexismo como estrutura de opressão às mulheres. "A ênfase no homem branco como explorador sexual em comunidades negras com frequência tira a atenção dispensada à exploração sexual das mulheres negras por homens negros" $"$. Assim muitas mulheres negras reconhecem as propostas sexuais agressivas feitas por homens brancos, vistas como negativas e como insultos, mas dispensam ou até mesmo veem como

\footnotetext{
${ }^{57}$ Ibid., 42-43.

58 Ibid., 94.

${ }^{59}$ Ibid., 96.

${ }^{60}$ bell hooks, E eu não sou uma mulher? Mulheres negras e feminismo (Rio de Janeiro: Rosa dos Tempos, 2019 ), 163.

${ }^{61}$ Ibid., 117.
} 
positivas, quando feitas por homens negros, o que muitas vezes torna violenta a opressão de mulheres negras em seus casamentos e relacionamentos sexualmente abusivos. O racismo como principal luta acabou permitindo convenientemente ignorar a opressão sexista dentro do próprio movimento negro. "Enquanto o racismo levou homens brancos a transformarem mulheres negras em alvo, o sexismo foi e é o que leva todos os homens a pensarem que podem verbal ou fisicamente atacar mulheres, com intenções sexuais, sem serem punidos."

Essas opressões que aparecem quando falamos de feminismo, raça, gênero, classe, etnia, território, não são acumulativas, "as intersecções das formas de opressão não podem ser vistas como uma simples sobreposição de camadas, mas sim como a "produção de efeitos específicos" ",63. As Formas de opressão não operam em singularidade, elas operam juntas. O racismo, por exemplo, não age sozinho, ele interage com outras ideologias e estruturas de opressão como o sexismo. Assim como mulheres amerifricanas no Brasil não tem as mesmas experiências de mulheres negras estadunidenses, mesmo que se encontrem algumas similaridades. Falar de feminismo decolonial, é falar das categorias marcadoras como não universais, mas que estão sempre imbricadas, não podemos falar de um racismo ou um sexismo universal, assim como não há como falar de uma mulher negra universal. Falar da dupla violência que a mulher negra sofre não quer dizer que essas opressões sejam somáticas ou universais, existem outros marcadores que são individuais e de experiências próprias dxs corpxs: negro, branco, latino, europeu, heterossexual, homossexual, do corpo lésbico, transexual, não-binário... Esta é uma forma de ver esses marcadores não universalizados, mas individualizados pelas experiências, seus pontos opressores e diferenças. Por isso as histórias são muito importantes, pontuam formas de existências, assim como reconhecem o lugar em que habitamos nas narrativas.

\section{Referências}

ADICHIE, Chimamanda Ngozi. O perigo de uma história única. Vídeo da palestra da escritora nigeriana no evento Tecnology, Entertainment and Design (TED Global 2009). Rev. Marina Nogueira e Viviane T. Mendes. $1^{a}$ edição. São Paulo: Companhia das Letras, 2009.

BRUNEL, Emma Álvarez y Nahuala. Afectos y disidencias sexuales jota-cola-mariconas en Abya Yala. Org. Joterismo: feminismos jotos y analquismo. $1^{\text {a }}$ edição. Buenos Aires: Madrágoras de Fuego, 2018.

CARVALHO, Joaquim de. "Maju da Globo é vítima de ataques racistas por apoiadores de Bolsonaro". DCM. https://www.diariodocentrodomundo.com.br/maju-da-globo-e-vitima-deataques-racistas-por-apoiadores-de-bolsonaro/. (Acessado em 15/07/2020).

FEDERICI, Silvia. Calibã e a bruxa: mulheres, corpo e acumulação primitiva. Título original: Caliban and the Witch: Women, the Body and Primitive Accumulation. Trad. coletivo Sycorax. São Paulo: Elefante, 2017.

\footnotetext{
62 bell hooks, E eu não sou uma mulher? Mulheres negras e feminismo (Rio de Janeiro: Rosa dos Tempos, 2019 ), 118.

${ }^{63}$ bell hooks, E eu não sou uma mulher? Mulheres negras e feminismo (Rio de Janeiro: Rosa dos Tempos, 2019 ), 117.
} 
FOUCAULT, Michel. Ditos e escritos, volume V: ética, sexualidade, política. Org. Manoel Barros da Motta. Trad. Elisa Monteiro e Inês Autran Dourado Barbosa. v. 5. Rio de Janeiro: Forense Universitária, 2012.

GONZALEZ, Lélia. "Racismo e sexismo na cultura brasileira". Revista Ciências Sociais Hoje, Anpocs (1984): 223-244.

Por um feminismo afro-latino-americano. Pensamento feminista hoje: perspectivas decoloniais (2020): 38-51.

HOOKS, bell. E eu não sou uma mulher? Mulheres negras e feminismo. Trad. Bhuvi Libanio. $1^{\text {a }}$ edição. Rio de Janeiro: Rosa dos Tempos, 2019.

KILOMBA, Grada. Memórias da plantação: episódios de racismo cotidiano. Trad. Jess Oliveira. $1^{\mathrm{a}}$ edição. Rio de Janeiro: Cobogó, 2019.

MASP. Histórias das mulheres, Histórias feministas. Org. Mariana Leme, Adriano Pedrosa, Isabella Rjeille. $1^{a}$ edição. São Paulo: MASP, 2019.

MORRISON, Toni. O olho mais azul. Trad. Manoel Paulo Ferreira. Rev. Ana Maria Barbosa

Carmen S. da Costa. São Paulo: Companhia das Letras, 2019.

PRECIADO, Paul B. Manifesto contrassexual. Trad. Maria Paula Gurgel Ribeiro. $2^{\mathrm{a}}$ edição. $3^{\mathrm{a}}$ impressão. São Paulo: n-1 edições, 2017.

SANTOS, Ana Paula. "Estudante é vítima de racismo em troca de mensagens de alunos de escola particular da Zona Sul do Rio." O Globo. https://g1.globo.com/rj/rio-dejaneiro/noticia/2020/05/20/estudante-e-vitima-de-racismo-em-troca-de-mensagens-dealunos-de-escola-particular-da-zona-sul-do-rio.ghtml. (Acessado 16/08/2020) 